\title{
THE UTILIZATION OF GARBAGE.
}

\author{
By Dr. Bruno Terne.
}

[A paper read at the meeting of the Chemical Section, held June 20, 1893.]

The immortal Justus Liebig, the founder of agricultural chemistry, and, indirectly, by his teachings, the creator of the industry of artificial fertilizers, combined in himself the qualifications of a most eminent chemist and a far-sighted national economist.

He transformed the chemical doctrines of plant nutrition at once to available figures for the farmer to show him in clear and indubitable sentences the laws of nature which compel him to restore to the soil what he has taken from it in the form of the products of the field.

His classical Chemical Letters are a monument he has erected for himself which will endure as long as the conditions of this globe remain the same as they now are. As long as the human race lives, the fundamental laws requiring the restitution to the soil in available form of the constituents of the plants as laid down by Germany's most eminent agricultural chemist will be written in golden letters in the history of all civilized nations.

In centuries to come the classical works of Liebig will be revered as the revelation of science respecting the practice of agriculture.

In his forty-seventh letter, Liebig refers especially to the relation of the consumption of the great cities to the products of our farms. From each hectare of wheatfield, the farmer, from the return of an average harvest transports from his farm to the consumers, 4,000 pounds of grain containing seventy pounds of mineral substances, mainly phosphoric acid and potash.

The refuse of a city of $\mathrm{I}, 000,000$ inhabitants will amount, in dried form, per annum, to $45,000,000$ pounds.

The constituents of this powdered material are $10,300,000$ pounds of mineral substances, mostly the mineral parts of 
breadstuffs and meat, which contain no less than $4,580,000$ of phosplatic salts.

The removal of this precious material (at the rate abovenamed) from the fields has been going on for centuries and only a small portion of it finds its way back to the fields.

It is folly to think that the loss of this material has had no detrimental influence upon the fertility of the soil.

I will quote from the tenth letter of Henry C. Carey, the American statesman and national economist, to the President of the United States. [J. B. Lippincott, Phila., I858.]

"The national economical question is not how much we can produce but how much is returned to the soil of the products annually.

"Labor used to rob the soil is worse than labor thrown away. In the latter it is a loss to the present generation, in the former poverty for the coming generation."

The same system which Carey condemned, in the above citation, of a large export of material without corresponding restitution of plant food to the soil continues to be practised in the corn belt of the West, while the cotton belt of the South and the entire East have been compelled to yield to the inexorable law of nature, and must now restore food to the impoverished soil to raise their crops.

The zone subservient to artificial nutrification of the soil grows wider and wider from year to year, since the waste of plant food-material grows more serious as our population grows denser.

What Carey so incisively pointed out thirty-five years ago, is as true to-day as it was then, but only the stress of absolute necessity, or the prospect of financial gain, will suffice to alter the system involving the extravagant waste of plant food-material which is now the rule with us.

For the sake of convenience we pollute our rivers and choose rather to suffer the consequences of drinking polluted water than to adopt rational measures to save, for the enrichment of our fields, the products which the law of nature has provided for the very purpose.

Our antipodeans, the much-despised Chinese, are much better practical economists than their civilized brethren 
In China, nothing is allowed to go to waste that is useful $\mathrm{t}$ the soil. The Chinaman's house is without the improver devices of the modern plumber, and his scent for nuisance. may not be so highly cultivated as ours, but by his systen: of the strictest economy, he manages to keep up the fertilit: of his soil to so high a degree, that the vast empire, not. withstanding that it possesses the densest population on the face of the earth, is entirely independent of all other nations, not only for the breadstuffs and other food supplics required for the sustenance of its people, but also for the fertilizing materials needed for its soil.

The Chinese, with the instinct of self-preservation, have been doing for centuries what Liebig and his followers taught the civilized nations of the world in the beginning and middle of the present century.

To-day we have fleets engaged in transporting phosphoretic and nitrogeneous materials from continent to continent; the services of the miner and the skill of the chemist are required to supply this food-material to our exhausted fields.

The nitrate mines of Chile, the phosphate beds of South Carolina and Florida, of Belgium and Russia, the mountains of apatite rock of Estremadura and the deposits of the same material in Canada, the potash salts of Germany and Hungary, are drawn into the service of agriculture. One of the most gigantic branches of the chemical industry has been built up in order to balance the debit and credit page of the rational farmer in the records of his culture.

But in seeking for remedies that will preserve the fertility of our fields, it is a remarkable fact that a vast amount of waste material which lies right at our feet, is not given a thought.

It is true that all the more valuable waste materials, such as bones, tankage, cracklings, cottonseed meal, leather, hoofs, horns, etc., have a stable market. But the poorer and much more abundant materials have been, and are now, almost entirely neglected.

We will to-night direct our attention to the question of the possibility of utilizing the garbage of our city, which, at the present writing, is the subject of much discussion. 
Until recently the garbage collected in this city has been used mainly as a feeding material for the fattening of pigs in the outskirts. For sanitary reasons, the Board of Health has banished the piggeries outside the limits of the county of Philadelphia. This is very commendable to free the city of a nuisance, which at the best was a very crude method of disposing of the material, and which, by the carelessness of those who make a business of it, certainly created a healthendangering nuisance; but the decision of the Board of Health made the disposal of the material very much more difficult than before.

The city of Philadelphia is divided into five districts for the collection of garbage. During the summer months, from June to September, the accumulation of a single district runs up to roo tons per day, while in the other months of the year the daily output varies, and in the middle of the winter falls to twenty-five tons per day.

A general average for the whole year is about 250 tons per day for the whole city.

This estimate we can safely use for calculation of returns but not as a basis for the construction of a plant, for which the maximum figures will have to be taken.

For the first district, comprising all that part of the city south from South Street, from river to river, a furnace for the cremation of garbage has been erected, situated on Washington Avenue and 'Twentieth Street.

Unquestionably cremation is the most complete system for destroying all organic substances, and doubtless to the extreme sanitarian the only method that should be adopted.

But what about the economical results? The daily operation of the furnace requires labor and fuel, the product of a cremator is a small quantity of ashes and worthless at that. Four or five per cent. of ashes is all that remains of the garbage when incinerated.

The American Incinerating Company, with headquarters at Washington Avente and Twentieth Street, has offered its product to the fertilizer trade. I have here a sample of these ashes which were sent to us. Our analysis yielded us:

Total phosphoric acid $==15.32$ per cent. $(=33.88$ per 
cent. phosphate of lime), potash 0.25 per cent., soluble in water.

I was astonished to find so little potash but the intense heat in the furnace has driven off a part of the alkalies as chloride vapors, otherwise the analysis should show at least four times as much.

This ash, even with fifteen per cent. phosphoric acid, has a very low market value because natural phosphates in bags, and ground to the finest powde, can be laid down at our doors at $\$ 5$ per ton.

The phosphoric acid of such low percentage is valueless for dissolving purposes because it will only yield practically a powder containing five to six per cent. of available phosphoric acid. This low product cannot be used for mixing fertilizers and it cannot be offered to the market when acid rocks containing thirteen to fourteen per cent. of available phosphoric acid are offered as low as $\$$ Io to $\$ 12$ per ton.

The products of the cremating process, therefore, will never become a commercial article. The question then arises, Can the same sanitary requirements be reached in another way? Without doubt they can, and, at the same time, the valuable comstituents of the garbage destroyed in the furnace can be saved.

The city.garbage, embracing all the refuse from the table and kitchen, changes its qualities considerably with the season. Just now we are in the vegetable period and the results of my experiments represent about the lowest results obtainable.

The experiments I have made are not laboratory experiments, but practical manufacturing experiments, handling at a time from six to twelve tons of material. I have been in the fortunate situation of being able to utilize, at intervals, apparatus designed for other purposes but very well adapted for the purpose of these experiments.

There is no secrecy about the principle of rationally utilizing garbage, and there are no new processes involved for which enormous patent fees will have to be paid.

The process is divided in two main operations:

(I) The separation of the grease by extraction. 
(2) The drying of the remainder to form directly a salable product.

The results I have obtained yielded me about seventeen per cent., on an average, of dry product from garbage tankage, a sample of which you have before you. This dry tankage is a very excellent fertilizing material. Its composition is:

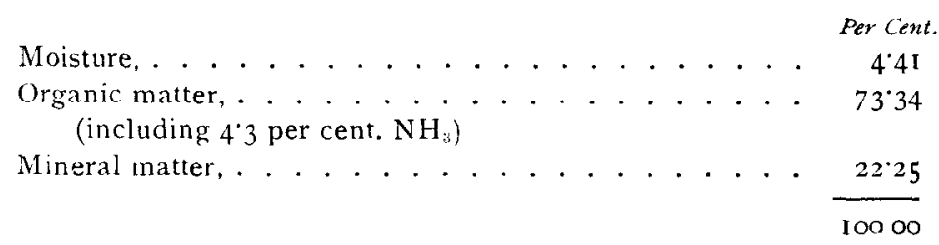

On a smaller scale than that which could profitably be carried on in Philadelphia, garbage is utilized successfully in this way in several places. I have received from Detroit samples of fertilizer made from garbage with as high as 5.37 per cent. ammonia, 6.08 phosphoric acid; and, at another time, $3.7^{6}$ per cent. ammonia, $3 \cdot 36$ phosphoric acid.

A specimen from Providence contained 3.55 ammonia, $3.3^{8}$ phosphoric acid; from other places, 3.86 ammonia, $3.5 \mathrm{I}$ phosphoric acid.

A fair average analysis, showing the minimum and maxi. mum of what we may export, is as follows:

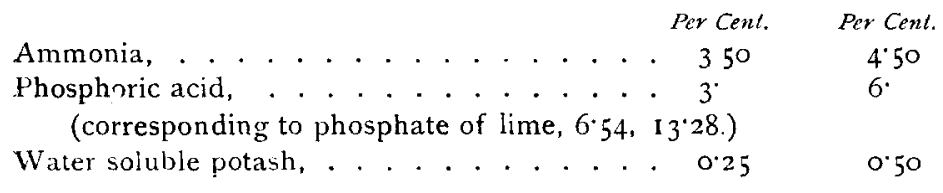

At the present market price the unit of ammonia is sold at $2 \cdot 60$. This would give, for the low grade, a market value of \$9.Io per ton; for the high grade, \$1I.Io per ton.

It is safe to say that at the present market these products will realize $\$$ Io per ton. I leave phosphoric acid and potash out of the calculation to give you the practical valuation.

This material is a most excellent fertilizer, not only shemically but also physically, and its usefulness in the manufacture of fertilizers is without limit.

The amount of garbage tankage produced from a ton of material as gathered up from the houses, placed at the low- 
est percentage (viz: about fifteen per cent.), amounts to 300 pounds per ton. One hundred tons per day will give 30,000 pounds or fifteen tons daily.

Taking the daily average of one district, we will average seven and one-half tons, or 2,250 tons per year; and for the five districts, I I,250 tons, having a market value of $\$$ I I 2,500.

Now, let us see what we restore to the fields in this amount of products.

The ammonia taken at four per cent. in one ton of the tankage contains eighty pounds of this important plant food, and I 2,500 tons, or the amount of production from the garbage of this city should be equivale?t to a saving of 9,000,000 pounds of ammonia, 9,000,000 pounds of phosphoric acid, and 500,000 pounds of potash.

All of this has been taken from our fields, and, if wasted or destroyed, represents so much loss to the community at large, but if this amount be regained and restored in proper form to the farm and garden it means so much saving. All of this amount must be restored from other sources in some way. If any waste material is worth saving it is surely the garbage of the cities, as I have endeavored to show.

There is another feature connected with this waste, viz: the regaining of the grease contained in garbage.

City garbage, at a low estimate, will yield three per cent. of a black grease, which you see in the samples before you. Even for this black grease, there exists a limited market at low figures for lubricating purposes (for car wheels). This black grease rarely contains much free fatty acid but it is by no means free from it. I have had samples containing over six per cent.

If the regular production should rise to such quantities as the garbage of the whole city will permit of producing, other uses must be found for this product, which, in the crude state has but a limited field of usefulness. There are ways and means known to the chemist, however, to improve this raw product, and the refined material made from it will readily find a market in competition with other greases.

The result of a chemical artifice of this kind, I take pleasurè in introducing to your notice in the sample before 
you. The method employed by me in this work is absolutely practical in respect of quick action, cheapness and positive results.

The grease stock so produced is very oily at $60^{\circ} \mathrm{F}$. It yields about seventy to seventy-five per cent. of this very fine oil which will find a ready sale. This oil will prove a puzzle to the best expert in the analysis of oils, for it contains traces of all oils and greases which enter the kitchen. It will challenge the reliability of all the color tests, the iodine numbers, etc., but in spite of its evasion of the methods of a Mailliau and Benedikt, it will find an excellent market.

The refined grease is a very fine soap stock, and a very crude product of a test in that direction I have with me. This soap is made solely from the same grease you have before you.

The rational mode of disposing of the city garbage is as simple as anything can be.

First, to gain all the grease, we must apply practical methods of extraction by known solvents; then, to save the fertilizer materials, we must employ the most rapid and economical methods to expel the eighty per cent. of water contained in the material.

Small amounts are easily handled; the difficulty arises when such enormous quantities stare one in the face. It is not, therefore, so much the chemical processes employed as the proper disposition of the plant, which must be well understood.

The stock delivered at the works must disappear in the process, on its arrival, and must never be permitted to rest for a moment until, after forty-eight hours, it is ready to be filled in to bags for shipment in the form you see before you in this sample. It is no more difficult to handle the enormous quantities of garbage than it is to handle the animal refuse of our city.

My experience of many years in handling materials of this kind in enormous quantities, first in Chicago, and since I 877 in this city, as the chemical manager of the largest works of its kind, permits me to speak advisedly on this 
subject, and I am prepared to stake my reputation as a technical chemist on the assertion that the utilization of our city garbage can be carried on as a financially successful operation for the saving of the valuable materials contained therein. How important the solution of this question is for the city of Philadelphia is well illustrated by the constant discussion of the subject in the daily papers.

Cremation, as I have shown, produces, at considerable expense, a valueless product. The rational chemical process yields, at no more cost, products which make a large figure in the housekeeping of a community.

Should we cast aside the warnings of an economist like Carey? Shall the teachings of Liebig and of all the prominent agricultural chemists of all nations have been in vain? I trust not, and believe not.

In this century of progress, with our knowledge of chem. istry, and with the most complete machinery at our disposal, it seems to me like a lapse into barbarism to destroy this most valuable material simply for the purpose of getting rid of it, while at the same time, we are eager to obtain these very same materials for our fields by purchase from other sources.

There is no doubt in my mind that this question of the disposal of our garbage can be solved by careful consideration of all points, by practical business men, to the advantage of the city authorities and the contractors for this work, to the fullest satisfaction of the health authorities, and to the benefit of the farmer.

Capital intelligently invested should be productive, not destructive. Instead of spending thousands of dollars for the erection of crematories to destroy, let us erect sanitary chemical works to preserve, this valuable material. There can be no danger to the public health in the conduct of a rational system for the utilization of garbage. All microbic carriers of contagious sicknesses are destroyed by a temperature of $212^{\circ} \mathrm{F}$., and this dry product you have before you is as harmless to the public health as the flour in the barrel.

My desire and expectation to-night, in making this 
presentation of an important industrial and sanitary problem, is to receive the endorsement of the Section, and later on, that of the Institute, to have you condemn the destruction of these valuable waste products, and approve, as the only right solution of this question, the preservation of these products displayed before you by a rational process of manufacture such as that indicated above.*

\section{ARTESIAN WELLS.}

By Oscar C. S. Carter.

Professcr of Geology and Mineralogy, Central High School, Philadelphia.

[Read at the stated meeting of the Chemical Section, held March 21, 1893.]

Within the last few years a great many artesian wells have been drilled in Pennsylvania to obtain pure drinking water for towns, villages and farms, and also for various manufacturing and industrial purposes, such as the manufacture of artificial ice, the brewing of beer and for use in steam and locomotive boilers. The two principal questions to consider in artesian water are the quality and the quantity. First, as regards the quality, there can be no doubt that water which filters through from 200 to 500 feet of rocky strata is free from all deleterious organic matter. Disease germs, which sewage in river water renders so common, are unknown in artesian water unless the well be drilled in a thickly populated district or be improperly cased. Artesian water comes to the surface clear and sparkling and is

* The ve:y able report on the above paper, which appeared in the Iublic Ledger, seems to have given to some persons interested in this question, the wrong impression, that it was presented in the interest of the company with which I am connected. Such is not the case.

This question. like any other question of interest to the company, has been fairly examined into by its chemical manager, but the company, for business reasons, would not undertake the utilization of garbage.

The chemical manager, therefore, was at liberty to make use of the results of his ex seriments for the benefit of the public at large, and did so after consultation with the president of the company and with his approbation.

B. T. 